\title{
The Adoption of BIM Technology in the Architectural Consultancy Firms in GCC Region
}

\author{
Mohamed Faisal Al-Kazee ${ }^{1, *}$, Racha Ramhamdani \\ ${ }^{1}$ Department of Architecture and Interior Design, College of Engineering and Architecture, University of Nizwa (UoN), P. O. Box 33, \\ P C 616 Nizwa, Sultanate of Oman \\ ${ }^{2}$ Department of Architectural Design, College of Architectural Engineering, University of Aleppo, Syrian Arab Republic
}

Received September 16, 2021; Revised November 1, 2021; Accepted November 21, 2021

\section{Cite This Paper in the following Citation Styles}

(a): [1] Mohamed Faisal Al-Kazee, Racha Ramhamdani, "The Adoption of BIM Technology in the Architectural Consultancy Firms in GCC Region," Civil Engineering and Architecture, Vol. 10, No. 1, pp. 280-288, 2022. DOI: 10.13189/cea.2022.100124.

(b): Mohamed Faisal Al-Kazee, Racha Ramhamdani (2022). The Adoption of BIM Technology in the Architectural Consultancy Firms in GCC Region. Civil Engineering and Architecture, 10(1), 280-288. DOI: 10.13189/cea.2022.100124.

Copyright $(\mathrm{C} 2022$ by authors, all rights reserved. Authors agree that this article remains permanently open access under the terms of the Creative Commons Attribution License 4.0 International License

\begin{abstract}
Nowadays, the construction industry market is in rising demand for the adoption of new construction technologies. Building Information Modeling (BIM) is one of the most technologies that are progressively being used for the majority of firms in GCC and worldwide. In this regard, BIM has promising applications for teamwork projects and stakeholders in the construction industry, especially architects. In addition, BIM plays an essential role in supporting them and facilitating the different procedures throughout the building life-cycle. However, our knowledge about architects' adoption of this technology is very limited. For this reason, the main aim of this paper is to identify the progress of architecture firms in BIM adoption and classify the characteristics of firms that have implemented BIM. Furthermore, the research method was mainly structured to cover several types of BIM studies and indicators about the spread of BIM applications in the local construction sector. Moreover, several questionnaires were designed to assess the level of BIM maturity in this region. The paper findings are expected to make all the project stakeholders aware of the current status and required steps towards BIM adoption at different levels in the GCC region. Additionally, the research results will pave the road to foster and enhance the BIM working field and facilitate its implementation by different disciplines within a wide range of architectural consultancy firms.
\end{abstract}

Keywords BIM, Architects, Architectural Firms,
Questionnaire

\section{Introduction}

GCC is not at the international level in this field [2,3], yet BIM is of great concern to professionals in the construction sector and GCC architects. If some of them are willing to put in place practices BIM, on the contrary, are strongly opposed to it. In a BIM project, architects are often the first actors to produce a digital model. Therefore, they are at the heart of the BIM dissemination process in the construction sector. However, few studies have focused on measuring their level of adoption of BIM. The purpose of this research presented here is to identify the average progress of architectural firms in their adoption of BIM, and the characteristics of the firms that implement these practices today. Firstly, the paper presents the state of knowledge on the adoption of BIM by architectural firms and how this knowledge and its gaps have determined our working method for the development and dissemination of a survey. Then, the results will be presented of the conducted survey. The second part concerns the progress average of architectural firms in adopting BIM. The third one discusses the links identified between the level of BIM use and certain demographic characteristics of agencies. 


\section{Methodology}

The study framework and method are mainly designed on a survey on BIM to be disseminated in architectural firms.

\subsection{Surveys on BIM and Architectural Firms}

BIM surveys have increased in recent years and several international studies are published regularly on the adoption of BIM. This is particularly the case with studies by Smart Market [10], and NBS [6]. Despite the abundance of data in these studies, it is often the entire sector that is studied (not specific professions) and architects are poorly represented. In the GCC region, a first indicator [4] provided an overview of BIM in the GCC sector, with a study carried out four years in a row to observe developments. The figures are sometimes presented by a state body, rarely by profession. Architects are therefore often included in the figures for project management. Autodesk's recent GCC study on BIM [1] involves a significant proportion of architects in its panel. The National Council of the Order of Architects regularly publishes figures on the architectural profession in this regard. However, the 2018 version of the report does not include any use of the term BIM. BIM adoption surveys rarely rely on diffusion and adoption theories of innovations. They do not provide an update on architectural firms, which are nevertheless essential players in the BIM transition. Studies on the architectural profession provide a lot of data on agencies but little concern about their digital and collaborative practices. The data available on the use of BIM by architects are therefore incomplete today.

\subsection{Context of the Study}

The main objectives of the comprehensive survey are to study and identify the following aspects:

1. The demographics of architectural firms.

2. The state of BIM practices and appreciation in the firms.

3. The factors that influence the decision.

Those answers will pave the road to start working in BIM and facilitate its implementation. Only part of aspect two is presented here which is the level of adoption of BIM in the branches and the characteristics of those who implement it. The questionnaire survey follows preliminary work on the state of the art, interviews, action research, and direct observation within architectural firms [2-5]. Qualitative methods indeed allow a first approach to the object of study [7,8], and are useful for problematizing the subject [8]. This preliminary work allowed us to develop useful hypotheses for the development of the questionnaire. In particular, we have worked on explaining the process of adopting BIM based on different theories of dissemination of innovation [3], as well as on referencing the factors that can influence the adoption of BIM [4]. These models were used as a basis for the construction of the questionnaire, part of the results of which are presented in this article.

\subsection{Protocol and Method of Distribution}

The survey has three main parts: characteristics of responding individuals and agencies, digital practices within agencies, and BIM implementation practices. The questionnaire was entered into Lime Survey, a professional online survey tool. The first version of it was administered to a panel of 5 people to verify the intelligibility of the questions before the broadcast. This made it possible to correct syntax and vocabulary points in the questions. An internet link was then created and distributed by several digital means. The GEU (Gulf Engineering Union) distributed it in early June 2021 to the 20,000 architects registered in their database, in two waves of emails spaced one week apart. These dissemination methods made it possible to collect 920 complete responses (completed questionnaire sent by the respondent). Incomplete responses were excluded as they would have introduced a bias in the analysis. The representativeness of the panel was verified by comparing the characteristics of the respondents (geographical origin and size of the agencies) with the official statistics of the GEU presented in newsletter 2021. The panel is identical to the official figures on the geographical distribution of the agencies but is 10 points fewer agencies of 1 to 5 people. Those who feel little concerned with the BIM topic may have been put off by the title of the survey. But the difference with the GEU figures remains small and the number of responses is substantial, and the representativeness of the panel is solid.

\section{The Adoption of BIM Practices in Branches}

This part is a general overview of the adoption of BIM practices in agencies. The software used by the latter as well as their computer-aided design practices were studied to deduce their BIM maturity level.

\subsection{Software Used by Architects}

We asked agencies to indicate the software they use to produce drawings documents during the design phases, as shown in Figure 1. Respondents could tick multiple modalities, as the interview phase revealed that many agencies used multiple software to perform similar tasks (Vector works and ArchiCAD for example). So, (46\%) of respondents indicate using AutoCAD, and (41\%) SketchUp; the two software are often used in combination. 
Also, (26\%) of respondents use ArchiCAD and (35\%) Revit. Respondents who checked "Other" indicated rendering tools or Draft sight, Power CADD, or Arc + software. First of all, we note that a majority of agencies work with AutoCAD. Quite a few agencies are using "BIM design" tools, and the gap between Revit and ArchiCAD is quite small. ArchiCAD, a software from the European supplier Nemechek, is historically more present than Revit. On the other hand, the agencies which have recently switched to a "BIM tool" may have Revit-oriented, remaining in the Autodesk environment while keeping a user interface similar to what was probably their previous tool: AutoCAD. During its BIM transition, GCC is also influenced by the international standards which have largely generalized the software solutions of the Autodesk suite, including Revit.

A third of the respondents (302 people) checked several software programs that allow you to perform identical tasks. Among them, and having had the opportunity to tick several response methods, some indicated that the tools are not shared by everyone at the agency. This is because the choice of tools is made on personal preference (41\%) or according to the needs in the agency. Also, project $(40 \%)$, because they are starting to implement BIM practices $(15 \%)$ or are experimenting with them to see if they are suitable $(15 \%)$ because they are at the end of the BIM transition (38\%), or that some have returned to pre-transition BIM tools (7\%).

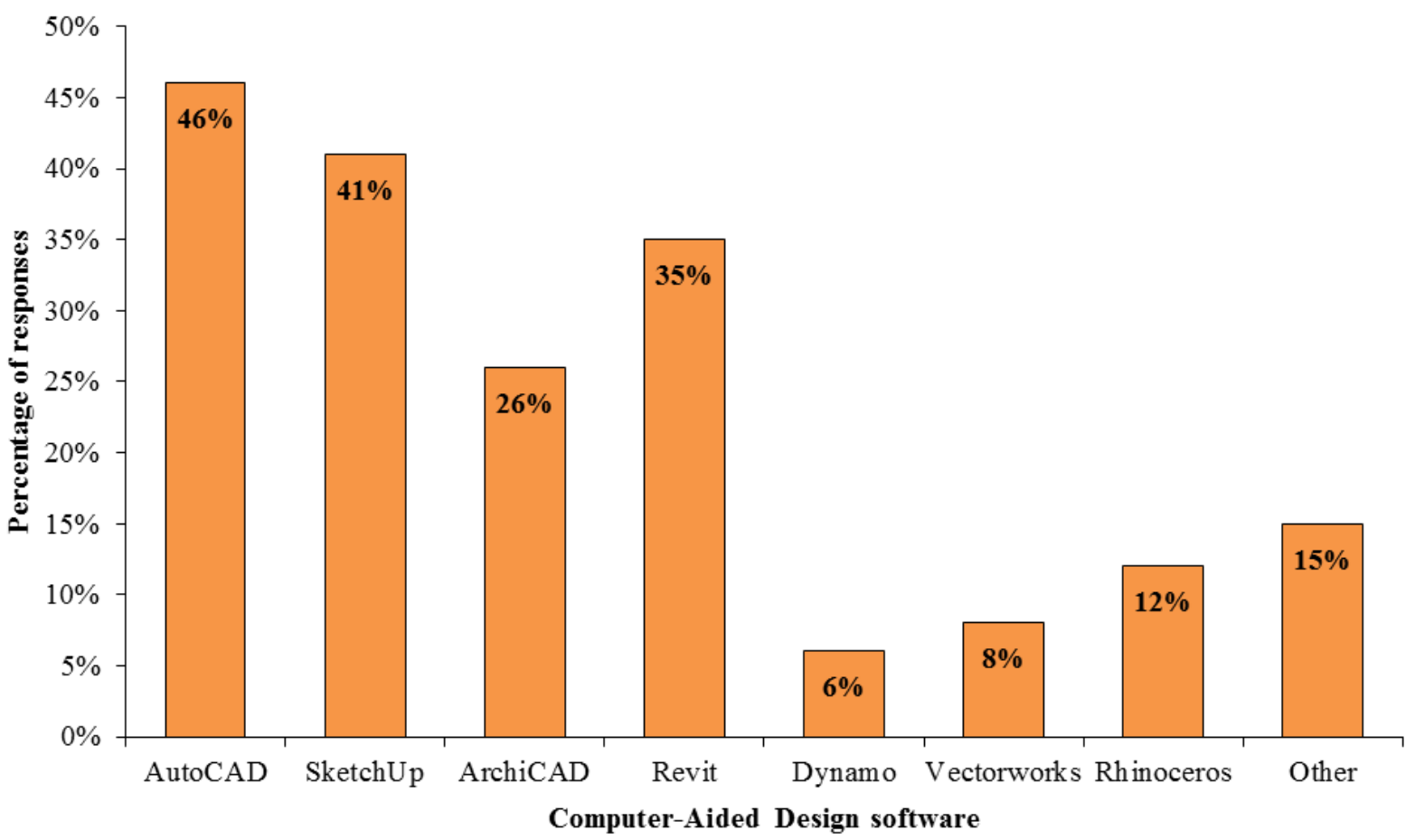

Figure 1. Computer-Aided Design software used by agencies 


\subsection{The Level of Use of BIM in Architectural Firms}

Here, we asked respondents to position their agency about different BIM practices. The responses were used to position GCC agencies in the process of adopting BIM.

\subsubsection{Method}

Several types of studies aim to determine the level of use of BIM by professionals. On a macro scale, the indicators provide a general overview of the spread of BIM in the construction sector. At the micro-scale, maturity matrices assess the BIM maturity of a business or even an individual. The purpose of this article is to determine the current state of adoption and understanding of BIM by architectural firms, it is a barometer. However, we have seen (section 2.1) that this type of study generally lacks a theoretical framework and consistency. Maturity matrices qualify a company's ability to implement BIM practices [13]. They do not assess their apprehension of BIM, nor their intention or difficulty in implementing it, which are central concepts in studying the adoption of BIM [2,3]. In addition, they assess this capability with a very high degree of granularity, difficult to implement, and not essential in a large-scale questionnaire survey. Therefore, they are neither suitable for determining the progress of the adoption of BIM by players in a sector, nor for determining their level of maturity in our case. In a questionnaire survey, it is necessary to reduce the number of questions to avoid dropping out. The maturity levels are therefore studied here with a low level of granularity. These are the BIM maturity levels (NDM) as defined by $[12,13]$ which are used here. They qualify the practices of the actors in three levels. Level 0 corresponds to computer-assisted drawing, level 1 in object-oriented modeling without exchanging digital models with partners, level 2 corresponds to a model-oriented collaboration, and level 3 to the synchronous collaborative use of a model stored in a network [9]. Here, we asked respondents to position their agency about eight characteristics and revealing practices of levels 1 and 2, as shown in Table 1 . Level 3 as described by $[9,14]$ has not been tested because preliminary interviews have shown it to be marginal; and level 0 was deduced from the absence of levels 1 and 2 .

The advancement of actors in the adoption of BIM is positioned in the process of adoption of BIM [3]. For each of the eight practices, the respondents were able to position themselves on the different phases of the adoption process, as shown in Figure 2. This is can be done by indicating that they do not know what it is (phase 0 ), that they know what it is, without more (1), that they think to set up one day this practice at the agency (2), that they wish to put it in place very soon (3), that it is excluded for them to set it up (3: freeze), that they are currently setting it up (4), that they tried to set it up but it did not work (4: freeze), or that 'they generalized this practice to the agency (5).

Table 1. Eight characteristic practices of levels 1 and 2 that were tested in our survey

\begin{tabular}{|c|c|c|}
\hline Practice & Description & Level \\
\hline P1 & $\begin{array}{c}\text { Produce plans and sections from 3D } \\
\text { using BIM 1 software }\end{array}$ & 1 \\
\hline P2 & $\begin{array}{c}\text { Perform (semi) automated measurements } \\
\text { from 3D }\end{array}$ & 1 \\
\hline P3 & Use a BIM collaborative work server \\
internal to agency & 1 \\
\hline P4 & $\begin{array}{c}\text { Enter non-geometric information in the } \\
\text { 3D model }\end{array}$ & 1 \\
\hline P5 & Transmit digital models to BETs (in IFC) & 2 \\
\hline P6 & Import / use a digital model received \\
from BETs & 2 \\
\hline P7 & Formalize file exchanges with partners & 2 \\
\hline P8 & Use a collaborative BIM platform with \\
partners
\end{tabular}

\subsubsection{Results}

Figure 2 shows the breakdown of GCC agencies in the process of adopting BIM. Maturity levels 1 and 2 are disseminated in a very similar way in the agency population, as shown in Figure 2. Level 1 is nevertheless more often implemented (phase 5) than level 2. Illogically, more agencies have indicated "not knowing what it is" (phase 0 ) regarding level 1 practices, only for level 2 . This result can be explained by the fact that level 1 has been mastered for a longer time; and level 2, the actual implementation of which is more recent, has been very popular in recent years, probably to the detriment of level 1. This also explains well the differences between levels 1 and 2 for phases 1,2 , and 3 . The adoption process can freeze at different stages, especially during the decision (3: freeze), or the implementation (4: freeze) [2,3]. The proportion of respondents excluding the implementation of BIM practices (3: freezing) is very high and concerns level 1 more strongly than level 2 . The number of respondents who tried to implement BIM practices without succeeding (4: gel) is quite low, and concerns slightly more level 2 than level 1. 


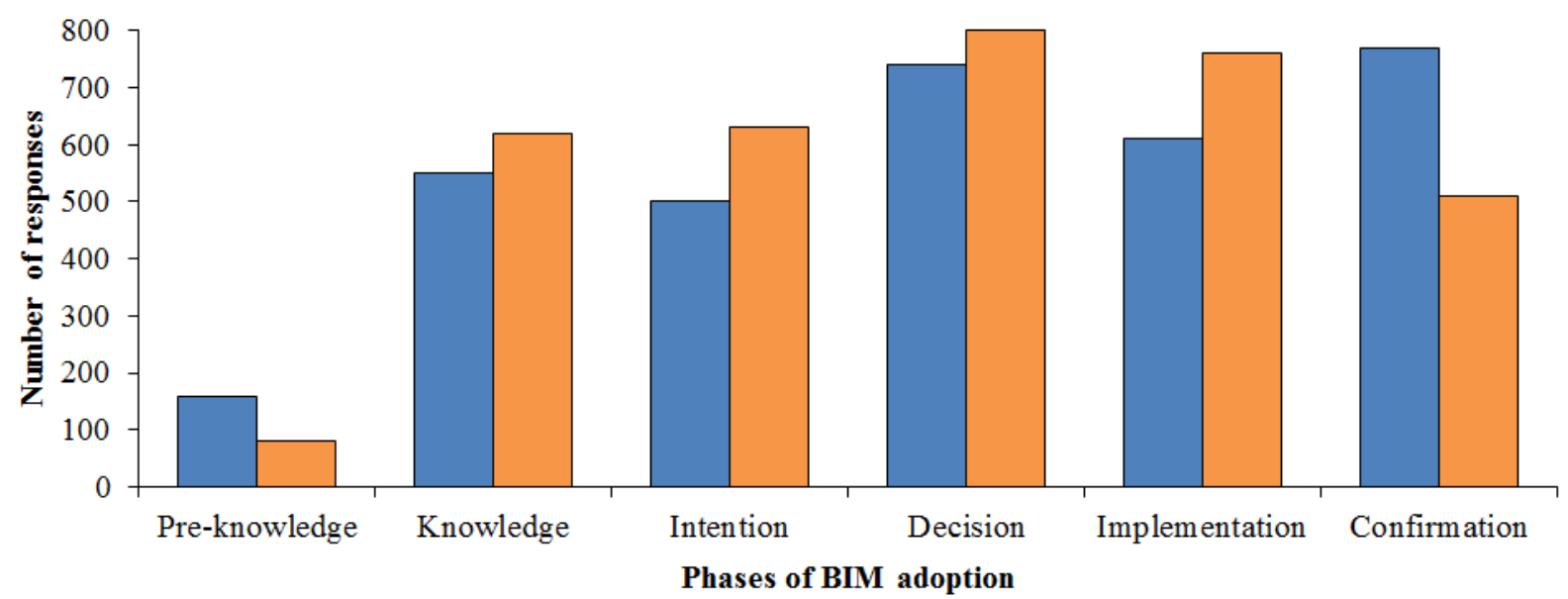

$\square$ Practices of Matu rity level $1 \quad$ Practices of Maturity level 2

Figure 2. A breakdown of the BIM adoption process of agency responses for practices characteristic of maturity levels 1 (P1-P4) and 2 (P5-P8)

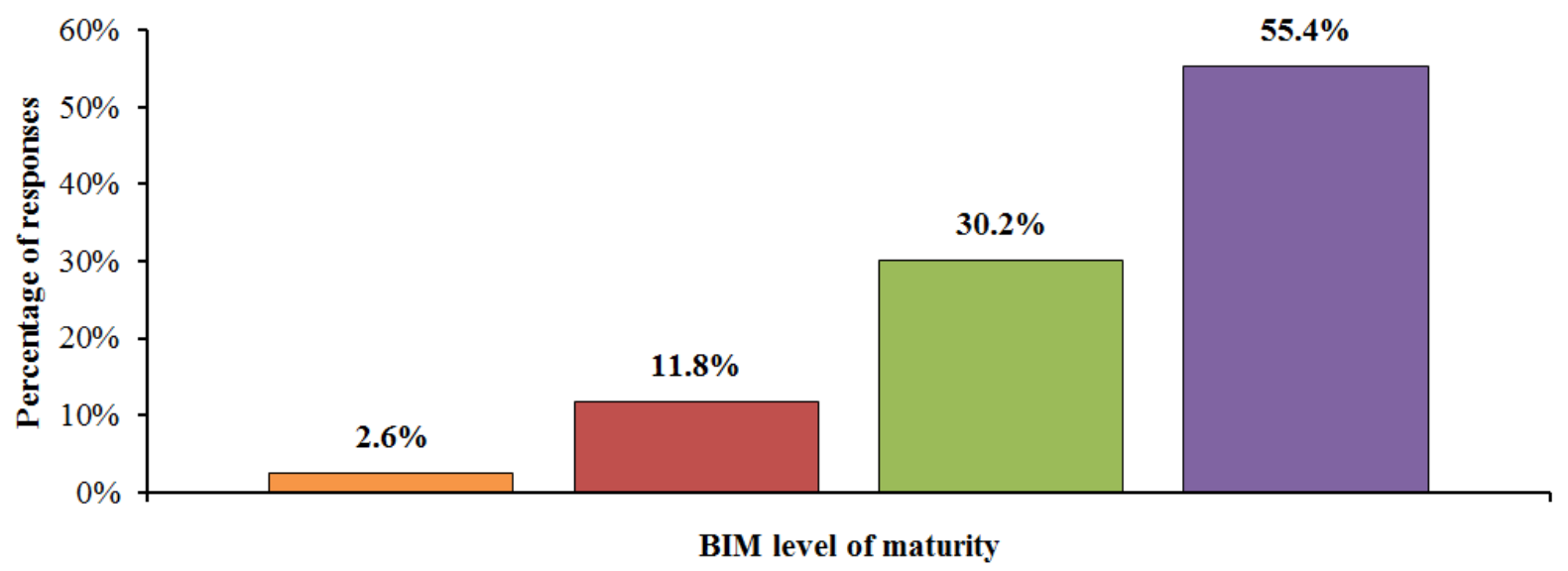

口Unknown $\square$ Level 2 Level $1 \quad \square$ Level 0

Figure 3. The level of maturity of architectural firms in our panel of respondents

The Lom of each agency was then calculated on these same responses. An agency is categorized as level 1 when it uses a BIM tool and has generalized at least one practice characteristic of level 1. An agency is categorized as level 2 when it meets the conditions for level 1 and has generalized at least two levels 2 practices. Agencies counted at level 1 are not at level 2. Those who are neither at level 1 nor level 2 are counted at level 0, or unknown if the data were missing.

Figure 3 shows the level of maturity of architectural firms in our panel of respondents. The color code used on this graph is retained on the following graphs. According to our calculation method, $(55.4 \%)$ of branches are at level $0,(30.2 \%)$ at level $1,(11.8 \%)$ at level 2 , and $(2.6 \%)$ are undefined. These figures are far removed from those of the Autodesk study which indicates that (65\%) of respondents practice BIM. The majority of agencies work at level 0 . Level 1 practices seem less attractive and less well known to agencies that do not implement them than those at level 2. Agencies that exclude the implementation of level 1 practices are more as many as for level 2 practices.

\section{Who Implements BIM Practices?}

The idea is that "only large structures could adopt the new technology because its cost would be so high" [11]. The survey made it possible to cross-reference information on the structure of the agencies with their $\mathrm{NdM}$ to reveal that BIM is not implemented only by these "big structures". Multiple logistic regressions were carried out for each NdM to characterize the associations between the levels of maturity of the agencies (previously calculated). Some of their characteristics, as follows:

1. The number of people at the agency.

2. The type and size of the projects that it carries out. 
3. The type of project management (public, private) with which it works and its mode of collaboration with the technical design offices (BET).

4. The renewal of staff and the hierarchical functioning of the agency.

5. The terms and conditions of internal collaboration and how their work is distributed.

6. The seniority of the manager and employees.

7. The level of participation of the manager in graphic production, and the (manager, employees) interest in digital tools.

In Figure 4, the most salient results are presented here. Employee interest in BIM is in our dataset, the variable most related to the maturity level of agencies. Only $(8 \%)$ of those who have employees who are reluctant or indifferent to BIM are at level 2, as shown in Figure 4. $(74 \%)$ at level 0 , But the statistic does not say whether it is the employees' interest in BIM that has driven (or slowed down) the manager's decision to switch the agency to BIM or if it was the implementation of BIM that made employees receptive. The interview phase, however, highlighted that employee reluctance can block the implementation of BIM at the agency and those proactive employees may instead convince the leader to commit his agency to a BIM transition.

The manager's level of participation in the agency's graphic production is the second variable most strongly associated with LoE 2 in an agency. It is five times more frequent to observe level 2 in agencies in which the manager participates in production than in those in which he does not use production tools at all, as shown in Figure 5. This observation also contradicts a hypothesis developed after the interviews: it appeared that the managers who manipulated the tools were reluctant to change them because, for them, this would mark their distance from the graphic production of the agency. The cross between the level of participation of managers in graphic production and their perception of the usefulness of BIM does not allow a conclusion, as shown in Figure 5.

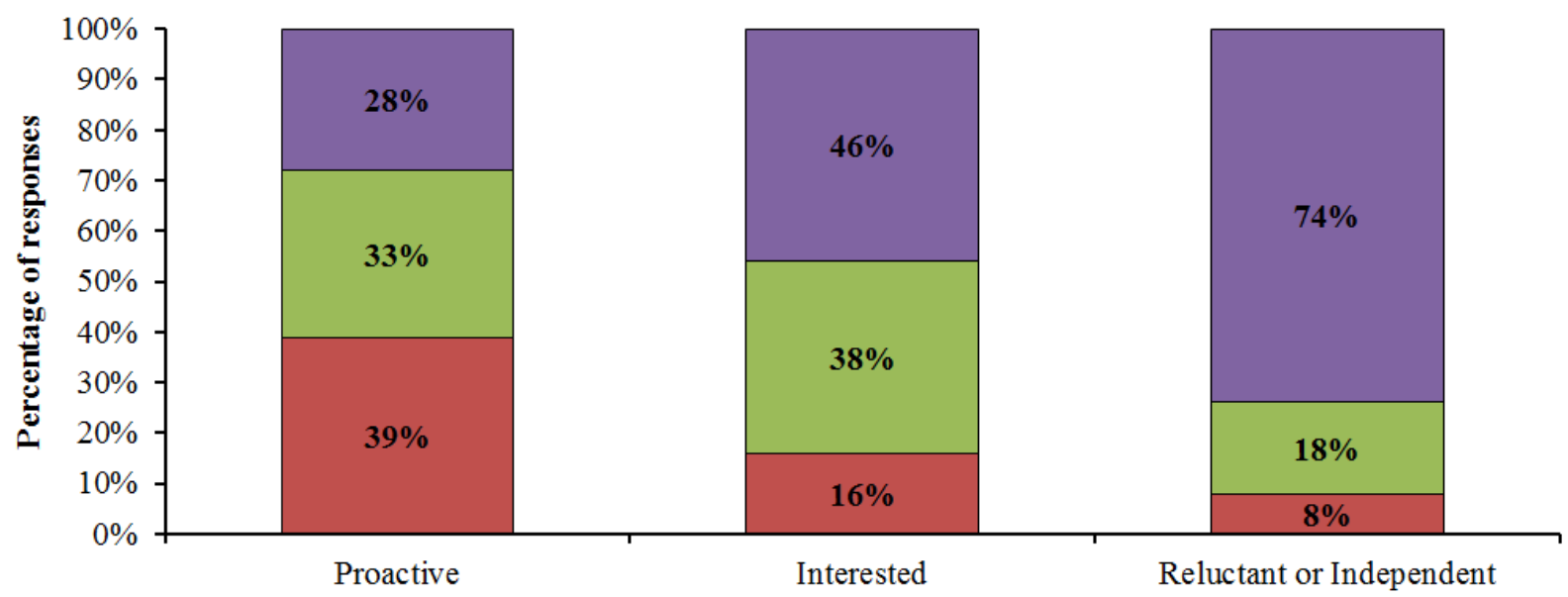

口Level 2 aLevel $1 \quad \square$ Level 0

Figure 4. Proportions of levels 0,1 , and 2 agencies about employee reaction to BIM
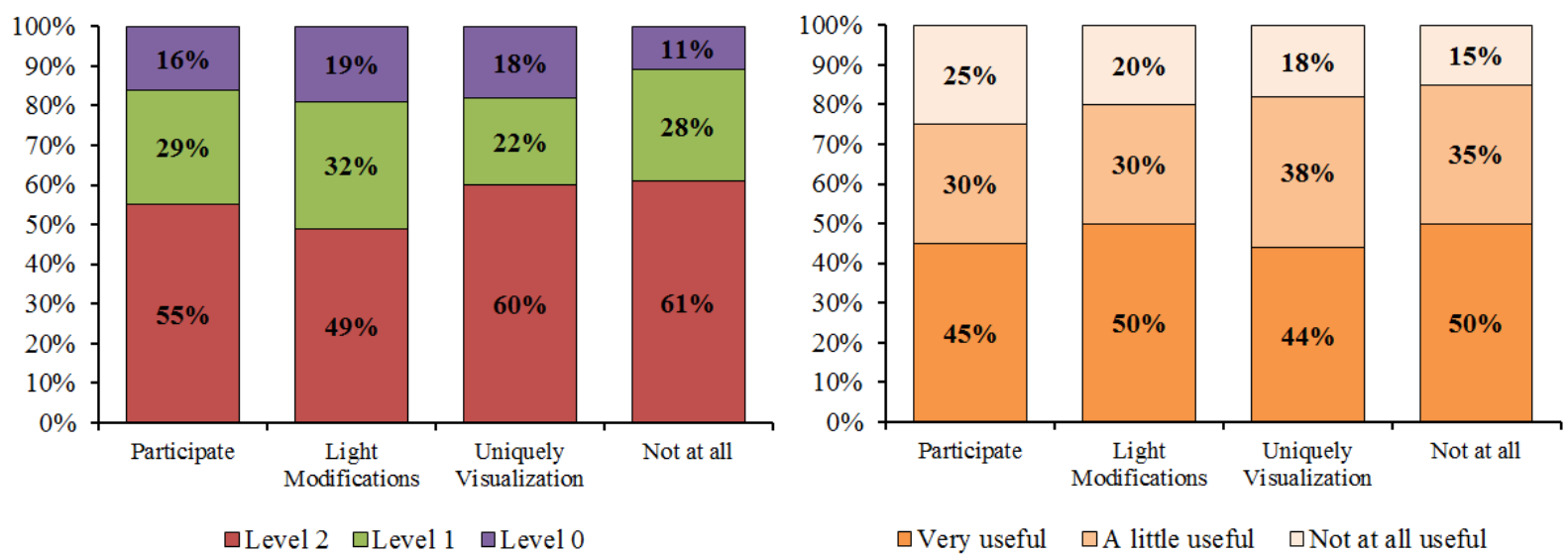

Figure 5. The agency maturity level compared to the manager's level of use of the agency's CAD tools (left), and the manager's perceived usefulness level of BIM compared to his level of participation in production agency graphic (right). 

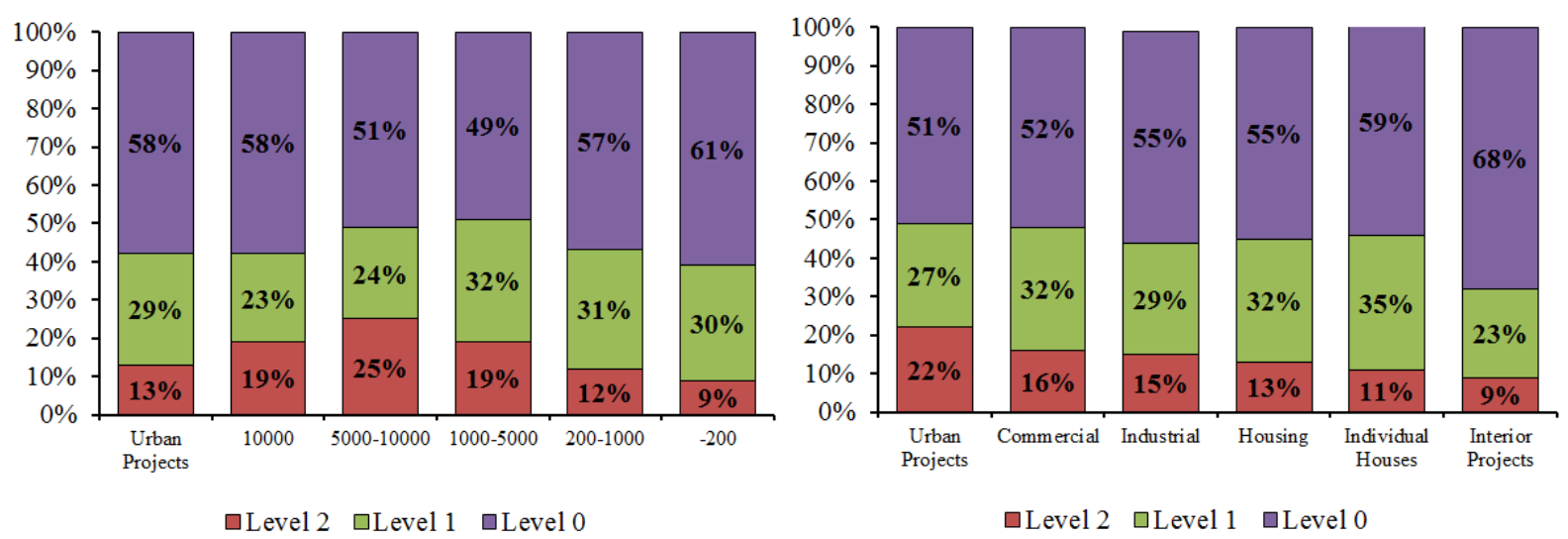

Figure 6. The Level of maturity of agencies concerning the average size of their projects (on the left) and concerning the types of projects often carried out (on the right)
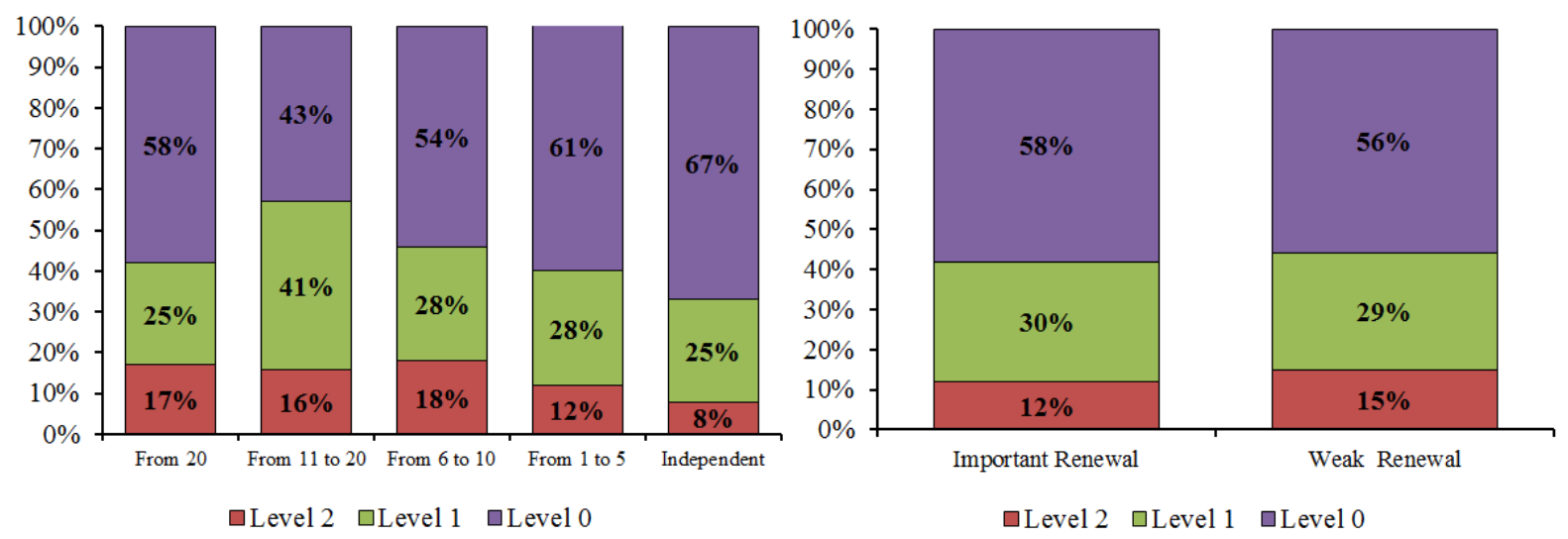

Figure 7. The level of maturity of agencies concerning the number of people working there (on the left), and the level of staff turnover or "turnover" (on the right)

The size of the projects the agencies are working on is also linked to their BIM practice. The more frequent an agency is carrying out small projects, the less likely it is to be BIM level 2, as shown in Figure 6. But beyond a certain large project scale, agencies are less frequently at level 2. Also, respondents indicated the types of programs the agency is working on (with the option to tick multiple responses). A quarter of the agencies that carry out urban projects are in BIM level 2. This proportion drops to only (8\%) for those that carry out individual houses. But regardless of the type of project involved, there are always between a quarter and a third of them at level 1. The type of project management (MO) for which the agencies work is linked to level 2: (7\%) of agencies that work mainly in private $\mathrm{MO}$ are at level 2, against $(15 \%)$ for those that work mainly in public MO.

The regression did not reveal a strong association between the size of the branches and their level of maturity, as shown in Figure 7. The self-employed working alone is less frequently at level 2 than others and small agencies are more often at level 0 . But the percentage of agencies at level 2 is constant, whether they have 6 or more people than 20. Level 1 is therefore not very dependent on the size of the agencies, even if it is a little more present in those of 11 to 20 people than the others. Even more striking, agencies with more than 20 people are more often in BIM 0 than agencies with 6 to 10 people. If the cost of BIM is difficult for small companies to bear, the largest ones face very strong inertia which makes any change complex.

A correlation was established between the type of hierarchy in the agencies and their level of BIM maturity. Those with a very vertical hierarchical system are rarely BIM level 2. The interviews nevertheless showed that agencies with a horizontal hierarchy have difficulties setting up common working methods. Regression analysis shows that agencies with high turnover are less frequently at level 2 than others. The interview phase made it possible to observe that the regular departure of employees prevented the anchoring of shared practices within the agencies and slowed down the implementation of BIM, which requires certain stability.

\section{Discussion}

The method for calculating the level of maturity proposed and implemented in this article has a low degree 
of granularity but is nevertheless sufficient here. Preliminary studies have identified that agencies adopt BIM in two successive modes. The first, a radical change shifts the agency to another level of BIM maturity especially when they change the main working tool or method. Then incremental, when they refine their practices, the 8 practices tested in this study. Therefore, reveal the level of maturity of agencies. According to the calculation method used here, (29\%) of agencies have adopted maturity level 1, and (12\%) have adopted level 2 . There are now more agencies that exclude the integration of level 1 within themselves than those that wish to put it in place very soon. However, the number of agencies in the process of transitioning to BIM or wishing to implement level 1 or 2 practices is significant. For agencies that have not implemented them, level 1 practices seem less attractive and less well known than those of level 2. Communication (commercial, government) carried out around BIM focuses on level 2, while level 1 carries a very significant potential for the agencies. Level 1 is also more reluctant than level 2. What turns architects off about BIM may be more about changing tools and drawing practices than talking to partners. Moreover, agencies that are at level 1 are generally not very reluctant at level 2 . Additionally, the level of BIM maturity of agencies is associated with some of their internal characteristics, especially for level 2. On the other hand, there are always around a quarter to a third of them at level 1, whatever the characteristic of agency tested. Those who are advanced in BIM practices carry out rather medium-large projects and often under public project management, with a manager who handles the graphics production tools a little. The maturity level 2 of branches is only weakly linked to their size. We even note that large agencies are more often at level 0 (and also often at level 2) than medium-sized agencies. High turnover and vertical hierarchical functioning are associated with low BIM progress. Also, Employee interest in BIM seems to be a big driver for agencies: it's common for proactive BIM employees to take the whole team with them. However, these initiatives are blocked in a vertical hierarchical system where the manager excludes a switch to BIM.

\section{Conclusions}

The questionnaire survey presented here made it possible to quantify and qualify the level of adoption of BIM in architectural firms in GCC. The majority of agencies do not work in BIM, and few agencies are at level 2. Many say that BIM is complex and too expensive. About a third of them now work with a "BIM tool"; but those which fully exploit its potential are still rare. The use of these tools and the implementation of level 1 practices is, in the dataset used, almost independent of the characteristics of the agencies, and agencies with many collaborators do not have more advanced BIM practices than others. Most agencies are in favor of BIM, but it also elicits strong and negative reactions from architects. These seem more related to the change of drawing tool than to exchanges with the project partners. Florent Champy noted, almost twenty years ago now: "if the intervention of the architect is justified by his capacity to develop drawings [since the identity of the profession is built on that of the architect-artist], computer-aided design, by considerably simplifying this work, harbors a threat. It is possible that architects' fears about maturity level 1 stem from the history of the profession and its connection to drawing. Nevertheless, it should be noted that many agencies are gradually adopting BIM practices: the impact of the historical trajectory of the profession must therefore also be qualified.

\section{REFERENCES}

[1] Autodesk (2019). Project management and project management in the BIM revolution - inventory, perceptions, and areas of development. 2019. Available at: https://www.autodesk.fr/solutions/bim/explore-building-de sign/bim-study.

[2] Azar, S., Khalfan, M. and Maqsood, T. (2011). Building Information Modeling (BIM): now and beyond. Australasian Journal of Construction Economics and Building, Vol. 2 (Issue 4), pp. 15-28.

[3] Bari's son, M. and Santos, E. (2011). BIM Teaching: Current International Trends. Gestão e Technologic de Projector, Vol. 6 (Issue 2), pp. 67-80.

[4] BATIACTU Group (2018). BIM in the construction sector. 2018. Available at:https://bit.ly/batiment-numerique-baro metre2018.

[5] Baton, Conrad and Kubicki, Sylvain (2014). Maturity of BIM practices: Modeling dimensions, collaborative practices, and technologies. SCAN'14, 6th Seminar on Digital Architectural Design. 2014. p. 45-56. Available at: https://hal.archives-ouvertes.fr/hal-01025675/.

[6] E. Kriel and B. Niles. (2008). Green BIM: Successful Sustainable Design with Building Information Modeling. Wiley Publishing, 2008, pp. 268.

[7] K. Jackob. Building Information Modeling: Technology Foundations and Industry Practice. 09 (3) (2018) 273-281.

[8] Kikongo, A., Zakharova, G., Kruglikov, A. and Plotnikov, S. (2017). Implementation of BIM-technologies in the educational program of the architectural university. In: 9th International Scientific Conference Building Defects (Building Defects 2017), Russia.

[9] Li. Bariba, Laing. R. Building Information Modelling (BIM) in Design, Construction and Operations. 06 (3) (2015) 102-110.

[10] McGraw Hill Construction (2010). The business value of 
BIM in Europe: Getting building information modeling to the bottom line the United Kingdom, France, and Germany. Smart Market Report. 2010.

[11] O. Newari, X. Zink. Building Information Modeling: Framework for Structural Design. 06 (3) (2015) 155-160.

[12] Sampaio, Z. (2015). Introduction to the BIM Concept in Civil Engineering Curriculum. International Journal of
Engineering Education, Vol. 31 (Issue 1), pp. 302-315.

[13] Succor, Bilal (2009). Building information modeling maturity matrix. Handbook of Research on Building Information Modeling and Construction Informatics: Concepts and Technologies, IGI Global. 2009. p. 65-103.

[14] V. Tarasov. (2011). BIM Fundamentals: Introduction to Building Information Modeling, Moscow, DMK, 2011. 